\title{
Modeling the Repair of a Crack in an HDPE Pipe
}

\author{
Samira Liamani ${ }^{1 *}$, Sahli Abderahmane ${ }^{1}$ \\ 1 Department of Mechanical Engineering, University of Sidi Bel Abbes, P. O. B. 89, Cité Ben M'hidi, 22000 Sidi Bel Abbes, Algeria \\ *Corresponding author, e-mail: samira.liamani@univ-sba.dz
}

Received: 18 May 2020, Accepted: 01 December 2020, Published online: 24 February 2021

\begin{abstract}
A pipe is a buried or aerial pipeline carrying goods, whether in liquid or gaseous form. Pipes are most often made from polymer tubes. These pipes prove to be subject to damage caused by a lack of material or crack thus calling for methods of repair or reinforcement. The objective of this study is to analyze by finite element analysis the presence of a horizontal crack in a high-density polyethylene pipe subjected to patch-corrected internal loading.

Part of this study is devoted to analyzing the Von Misses stress distribution along a horizontal line, the applied loading type effect, the orientation of the fibers and the nature of the patch have been highlighted.

The second part of our study is based on the calculation of the J-Integral where the same parameters of the first part were considered. The results clearly show that the mechanical characteristics of the composite must be optimized to provide an effective repair safely and allow relief of stress concentrations at the crack front.
\end{abstract}

\section{Keywords}

repair, HDPE, patch, J-integral, crack, pressure

\section{Introduction}

Polymer pipes are increasingly used for various applications, such as the water, gas and high pressure containers industries. The use of polymer pipes under cruel environmental conditions can expose it to various types of damage, such as mechanical damage and cracks [1-4].

Since damage is the main cause of crack growth, some researchers have focused on failures and risks associated with HDPE pipe used for trenchless rehabilitation and new construction technologies $[5,6]$. Others have studied the breakage of the HDPE material [7-12].

In what follows, we analyze numerically three-dimensionally by the finite element method, the mechanical behavior of high density polyethylene, subjected to internal loadings. The mechanical loading consists in asking a pipe in this polymer an internal pressure.

\section{Finite element method}

\subsection{Geometry and mechanical properties}

As previously reported, this work was done using this code. The polymer pipe (HDPE) is characterized by a length $(L=200 \mathrm{~mm})$, an inner radius $\left(R_{i}=80 \mathrm{~mm}\right)$, a thickness $(t=9.1 \mathrm{~mm})[13,14]$. This pipeline has a horizontal crack repaired by three composite types. The dimensions of the patch are length $L_{\text {patch }}=200 \mathrm{~mm}$ and thickness $e_{\text {patch }}=2 \mathrm{~mm}$.

The use of the composite patch to repair damaged pipes is widespread today because of their important properties and high performance in strength and rigidity. In this analysis, we have assumed three types of laminated composites namely: Glass/epoxy, Carbon/epoxy [15] and Aramid/ epoxy [16], the mechanical properties of the pipeline as well as the patch are shown in Table 1 [17, 18]. In 2001 Friedrich Heisterkamp and Tadeu Carneiro [19] reported an internal operating pressure value of the pipes which ranges between 2 and $12 \mathrm{MPa}$. For this reason, our choice was based on these load values for the pipe study (5,10 and $15 \mathrm{MPa}$ ).

A 3D elastic model has been developed using the ABAQUS program [20] to account for the geometric and material behavior of composite repaired polymer pipe. FEM has been used to simulate the fracture crack path [21] in various crack analysis problems with different stationary inclined crack angles in pipe. These three types of composites were chosen to repair the cracked pipe and analyzed in terms of variation of the energy release rate ( $J$-Integral). 
Table 1 Mechanical properties of different materials

\begin{tabular}{|c|c|c|c|c|}
\hline & $\begin{array}{c}\text { Pipe } \\
\text { (HDPE) }\end{array}$ & Glass/epoxy & Carbon/epoxy & Aramid/epoxy \\
\hline $\begin{array}{l}E 1 \\
{[\mathrm{GPa}]}\end{array}$ & 0.5 & 150 & 109 & 76 \\
\hline $\begin{array}{l}E 2 \\
{[\mathrm{GPa}]}\end{array}$ & & 25 & 8.819 & 5.5 \\
\hline $\begin{array}{l}E 3 \\
{[\mathrm{GPa}]}\end{array}$ & & 25 & 8.819 & 5.5 \\
\hline$v 12$ & 0.38 & 0.21 & 4.31 & 2.3 \\
\hline$v 13$ & & 0.21 & 4.314 & 2.3 \\
\hline$v 23$ & & 0.21 & 3.2 & 2.3 \\
\hline $\begin{array}{l}G 12 \\
{[\mathrm{GPa}]}\end{array}$ & & 7.2 & 0.342 & 0.34 \\
\hline $\begin{array}{l}G 13 \\
{[\mathrm{GPa}]}\end{array}$ & & 5.5 & 0.342 & 0.34 \\
\hline $\begin{array}{l}G 23 \\
{[\mathrm{GPa}]}\end{array}$ & & 5.5 & 0.38 & 0.34 \\
\hline
\end{tabular}

\subsection{Mesh}

The mesh used is shown in Fig. 1. The circular shape of the composite patch is identifiable in Fig. 1. A regular mesh is made for the whole structure. This mesh remains the same throughout the calculation in order to avoid any influence of the mesh on the results. At this level, let us specify that the mesh is of quadratic type (hexahedrons).

The crack in the pipeline causes a geometrical singularity causing a stress concentration of the crack.

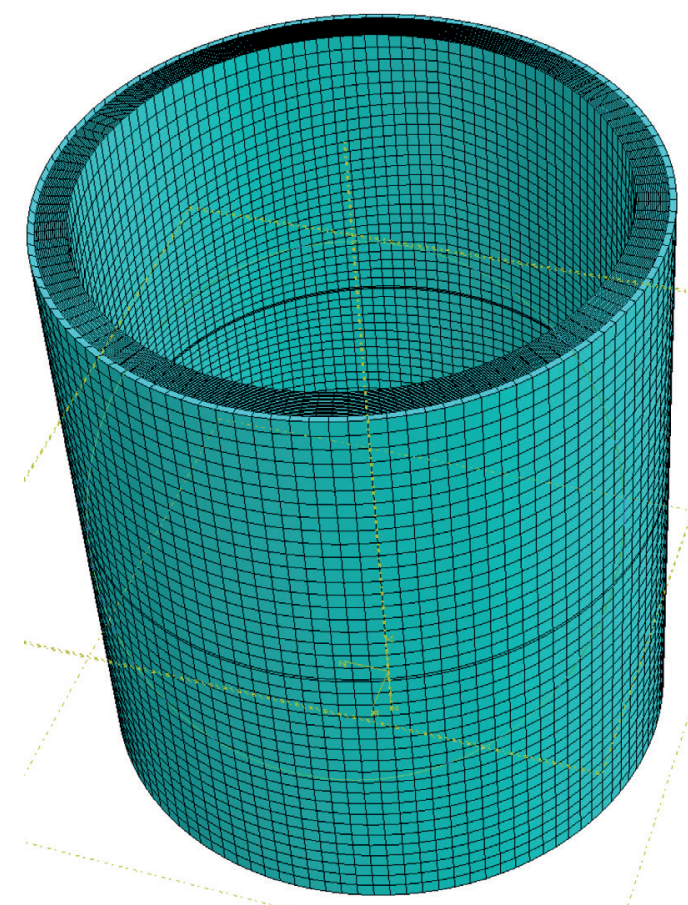

Fig. 1 Type of element used for mesh generation
The total number of element of the structure being 114873 that is to say 110240 elements for the pipeline, and 4633 elements for the patch.

Any finite element calculation requires the definition of boundary conditions. The studied structure was subjected to a loading modeled by a pressure, defined on the inner surface of the pipe. The $z$ direction of the pipe is applied symmetric boundary conditions (displacement and rotation in the $z$ direction is blocked).

\section{Results and discussion}

\subsection{Von Misses stress distribution}

In order to study the effect of the mechanical changes of the patch on the charge transfer from the plate to the patch, the distribution of Von Misses equivalent stresses for different types of patch was presented in Fig. 2 taken only the case of a crack equal to $10 \mathrm{~mm}$ and an internal load of $15 \mathrm{MPa}$ for the effect of two orientation of the fibers $\left(\alpha=0^{\circ}\right.$ and $\left.\alpha=45^{\circ}\right)$.

We chose the orientation values of the fibers according to all the studies that used $0^{\circ}, 45^{\circ}$ and $90^{\circ}$ as reference value $[17,22]$.

The first remark is that the distribution of the stresses in the different values of orientations of the fibers is almost identical whatever the modification made to the patch.

The constraints of Von Misses are maximum for the Aramid-epoxy type patch, and they are very high (up to $65 \mathrm{MPa}$ ) compared to the values obtained by the carbon-epoxy patch $(25 \mathrm{MPa})$. By going to patches where the mechanical properties increase, the value of the stress decreases. The stresses are concentrated at the crack tip for the three types of patch.

The effect of fiber orientation of the composite on the Von Misses stress distribution in the composite is shown in Fig. 3. Note that the stress level absorbed by the $45^{\circ}$ composite is much higher than in the $0^{\circ}$ fiber composite. This explains that fiber composites of $0^{\circ}$ are better than composites at $45^{\circ}$ because it absorbs the maximum of constraint, it should also be noted that the composites at $0^{\circ}$ do not show high peaks in the vicinity of the cracks, which is visible for composites at 45 degrees.

The durability of composite patch repairs to damaged structures depends on the nature of the loading applied. In this part we calculate by the finite element method the distribution of Von stress placed for a crack length of $10 \mathrm{~mm}$ and a patch of carbon-epoxy type for different loading value applied. 


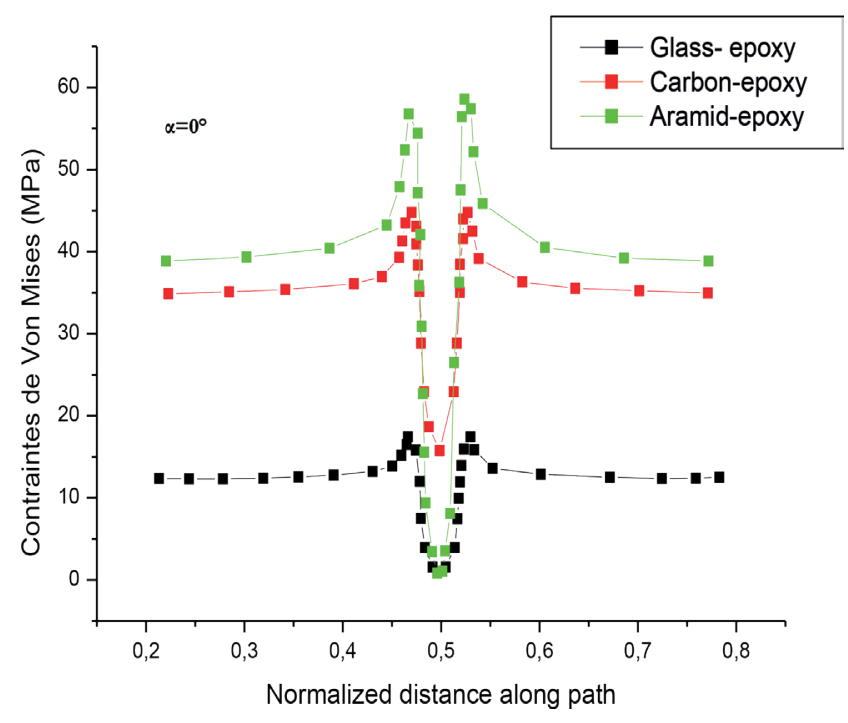

(a)

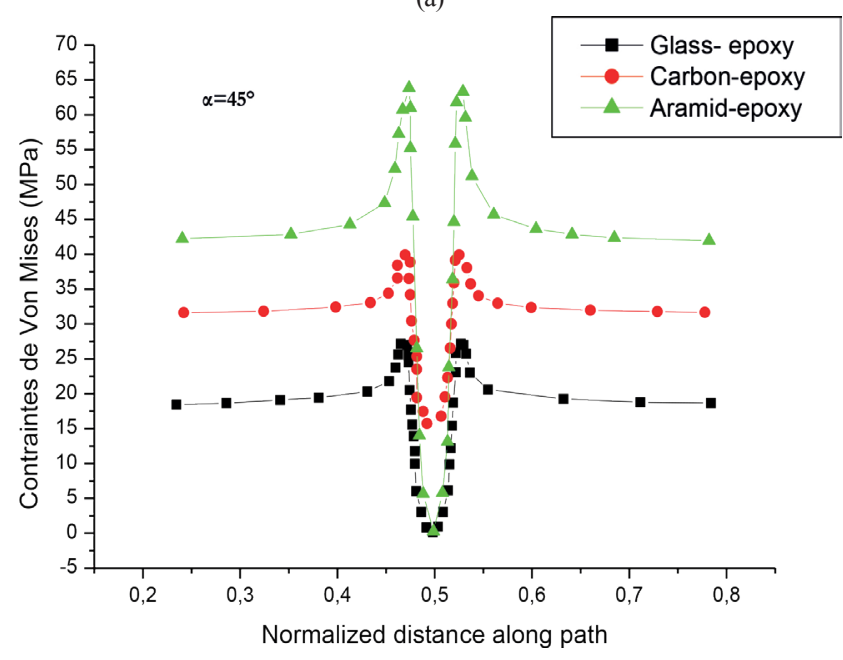

(b)

Fig. 2 Comparison of stress distributions for the three patch models

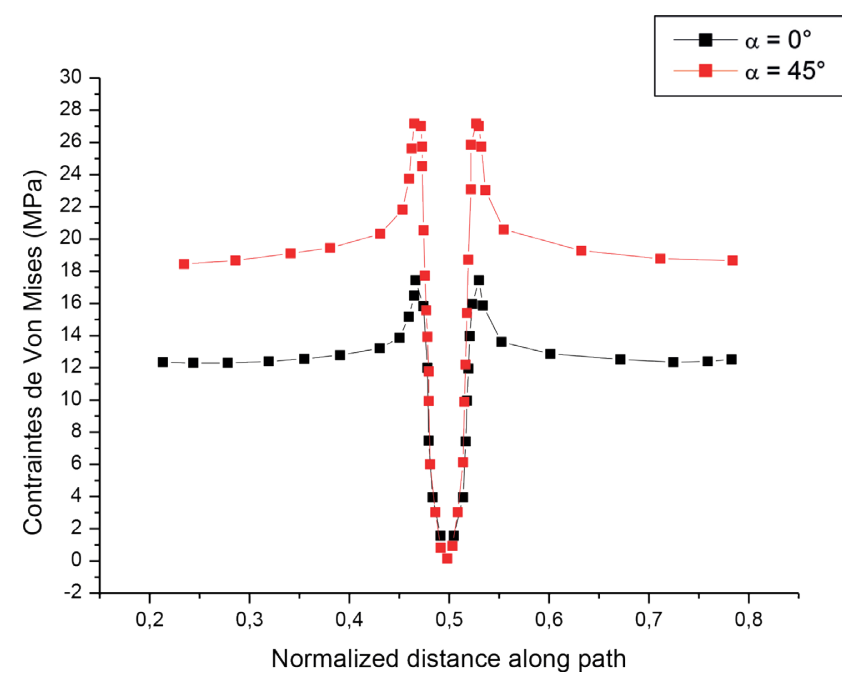

Fig. 3 Stress distributions in the composite as a function of fiber orientation
Fig. 4 shows the stress distribution for the different internal pressures applied to the model studied for $45^{\circ}$ fiber composites is much greater than that of $0^{\circ}$ fiber composites. The maximum values of these stresses are presented by pipes with internal pressures $P=15 \mathrm{MPa}$, a decrease of these pressures leads to a decrease in the stress distribution. Therefore, the results obtained show that the distribution of the von misses stresses for the different types of patch are generally in good agreement with the predictions of Kaci et al. [17].

\subsection{Effect of crack opening}

For a better illustration of the mechanical behavior in failure of HDPE, we studied the propagation of a crack for the same loading conditions, and simulation as those used

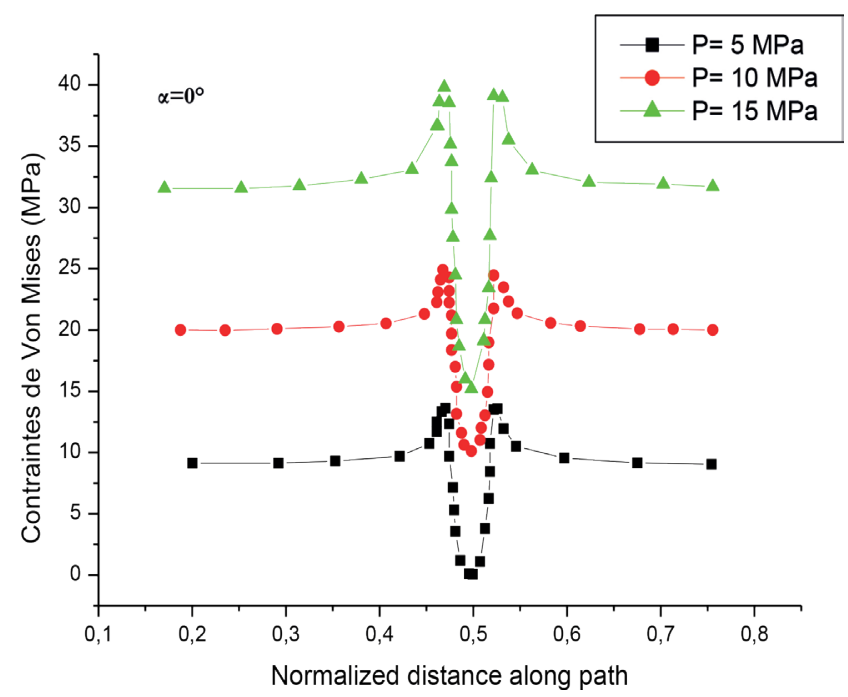

(a)

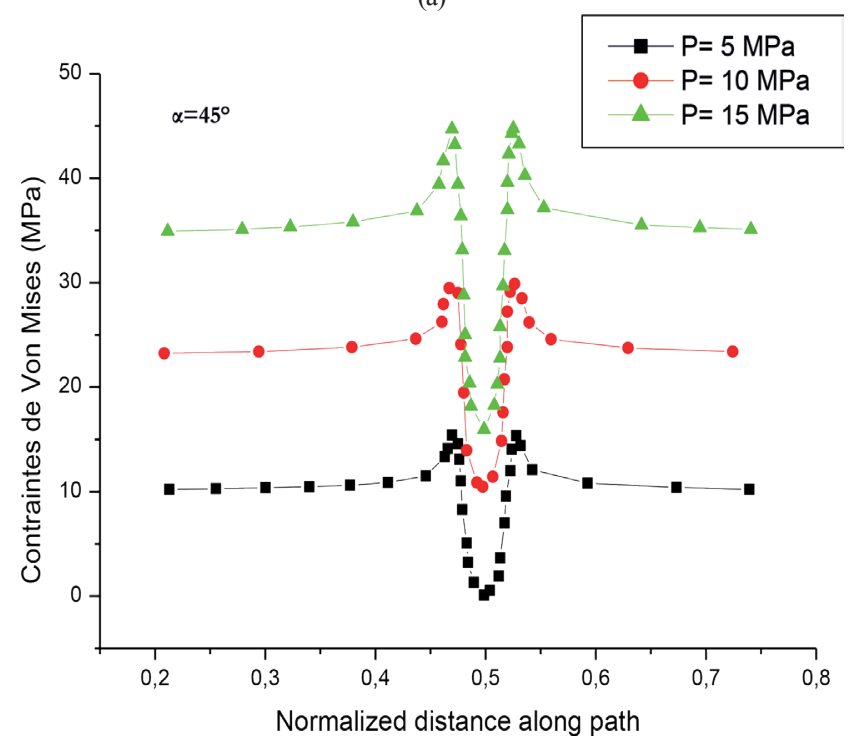

(b)

Fig. 4 Comparison of stress distributions for different applied pressures 
previously. We carried out a comparative analysis of a cracked pipe and the other cracked and repaired by patch allowing the determination of the stress intensity factor in opening mode $(K I)$. The Fig. 5 shows the behavior of the stress intensity factor "FIC" with respect to the crack opening " $a$ ".

The beneficial effect of the patch is clearly visible because the stress intensity factor decreases sharply, because the patch absorbs the forces transferred by the pipe as the crack length $a$ increases. The maximum reduction in the stress intensity factor is $75 \%$.

In Subsection 3.2, we compared our results obtained using the compute of the stress intensity factor and the integral $J$ by the finite element method, with those reported by EL-Bagory et al. in 2015 [2], and which have does real work. The results are shown in Table 2.

In the case of welded specimens, there is a marginal difference by at least $6 \%$ between the value of the stress intensity factor in the opening mode measured by the finished element method of an HDPE pipe repaired by patch is that measured by EL-Bagory et al. [2], for a standardized length chosen equal to 0.75 . However, the calculation of the value of the $J$-Integral measured on the basis of the welded CTPB specimen is greater than those measured by an HDPE Pipe by at least $10 \%$.

\subsection{Effect of fiber orientations on the value of $\boldsymbol{J}$-Integral} First, we tried to study the breaking behavior of a high-density polyethylene pipe for different lengths of the crack

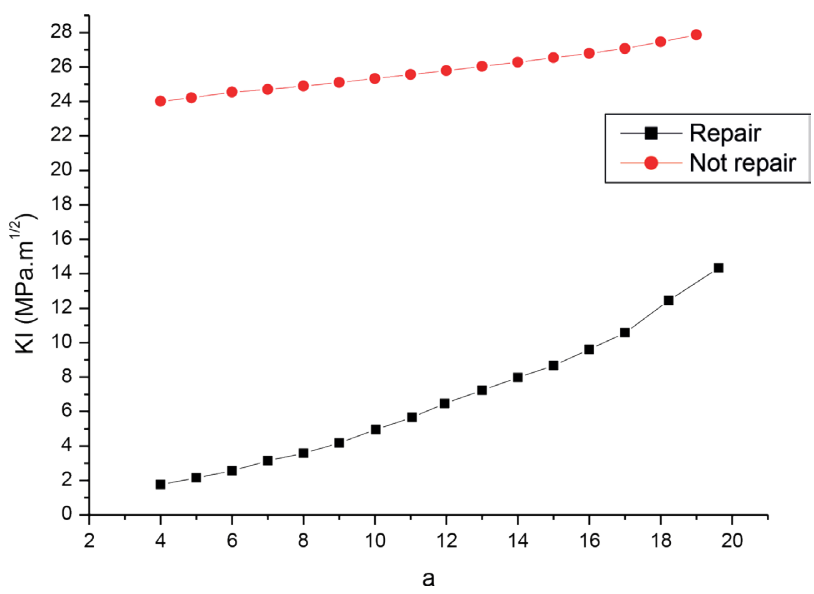

Fig. 5 Variation of the stress intensity factor KI as a function of the crack opening

Table 2 Mechanical properties of different materials

\begin{tabular}{lccc}
\hline Type of specimen & $a / w$ & $K I\left(\mathrm{MPa} \mathrm{m}^{1 / 2}\right)$ & $J\left(\mathrm{~kJ} / \mathrm{m}^{2}\right)$ \\
\hline $\begin{array}{l}\text { Welded CTPB } \\
\text { specimen }\end{array}$ & 0.75 & 0.953 & 17.77 \\
PEHD Pipe & 0.75 & 1.15 & 14.23 \\
\hline
\end{tabular}

and we calculated by simulation the corresponding values of $J$-Integral (in $\mathrm{N} / \mathrm{mm}$ ), for this purpose to use a glass-epoxy patch with different fiber orientations and different values of the loading applied as shown in Fig. 6.

Fig. 6 shows the variation in the value of the $J$-Integral as a function of the normalized length $(a / w$ where $a$ is the length of the crack and $w$ the maximum length of the crack expressed in $\mathrm{mm}$ ) for the three cases of fiber orientations $\left(\alpha=0^{\circ}, 45^{\circ}\right.$ and $\left.90^{\circ}\right)$ with different internal pressures $(P=5,10$ and $15 \mathrm{MPa})$. It was shown by Abd-Elhady et al. [4] the efficiency of composite repair patch for reducing $J$-integral increased with an increase in the crack length for the same patch dimensions and location. According to the results of Fig. 5, it is clear that the shape of the curves varies in the same way for the values of the applied pressure except that the values change. The internal pressure $P=5 \mathrm{MPa}$ has lower values than for the case of the loadings equal to 10 and $15 \mathrm{MPa}$.

It is also noted that the value of the $J$-Integral increases if the length of the crack increases. The maximum value of $J$ is for the case of the orientation of the fibers $\alpha=45^{\circ}$. For both fiber orientations $\alpha=0^{\circ}$ and $\alpha=90^{\circ}$, the value of $J$-Integral is almost the same regardless of the value of the normalized length $a / w$ (Fig. 6), what has been shown by Sharma et al. [23] that lateral propagation of damage in the composite can be decreased by separating two layers of composite with $90^{\circ}$ and $0^{\circ}$ fiber orientations by two layers with $45^{\circ}$ fiber orientations.

\subsection{Effect of patch type changes on the $J$-Integral value}

In order to clearly see the different parameters that can influence the value of $J$-Integral, the variation of the $J$ as a function of the normalized length for the three different types of patch has been presented in Fig. 7. We took the case of an internal pressure equal to $5 \mathrm{MPa}$.

It is clear that whatever the nature of the repair patch, and whatever the orientation of the fibers, the value of $J$-Integral increases, and this increase is more remarkable when the length of the crack characterized by the ratio $(a / w)$ (normalized length) exceeds 0.2. This value is maximum for the case of the repair patch type Aramid-epoxy and more particularly for the fiber orientations which are equal to $0^{\circ}$ and $90^{\circ}$.

The nature of the composite plays a role in reducing the $J$-Integral. The patch which has high mechanical properties better absorbs the stresses at the level of the damaged zone and thus minimizes the value of $J$. This characteristic presents the same values for fiber orientations $\alpha=0^{\circ}$ and $\alpha=90^{\circ}$. 


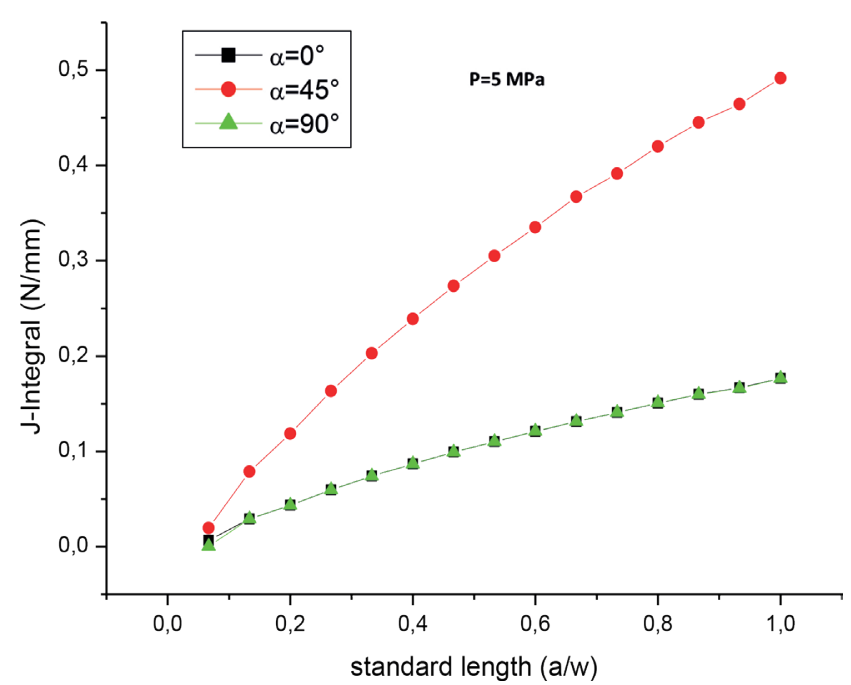

(a)

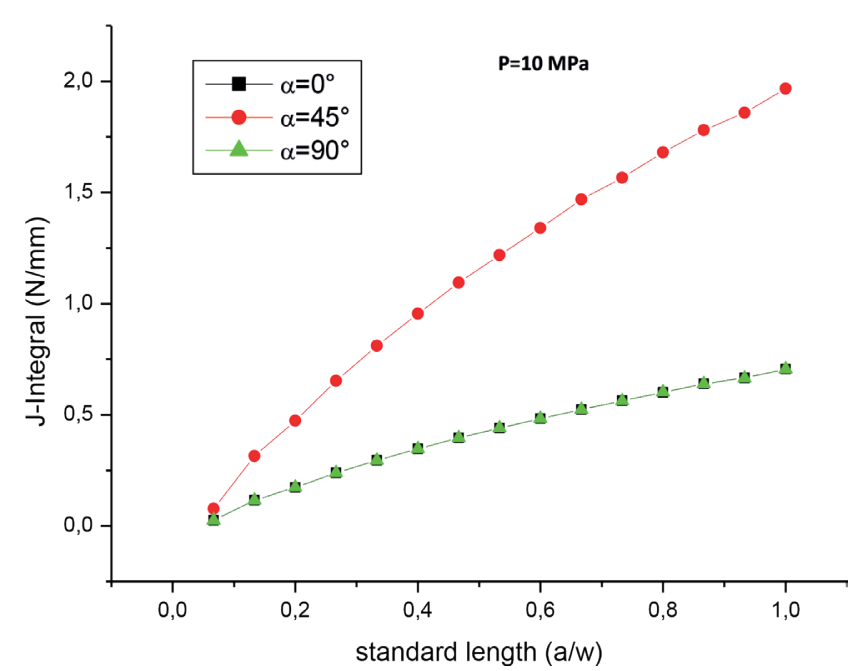

(b)

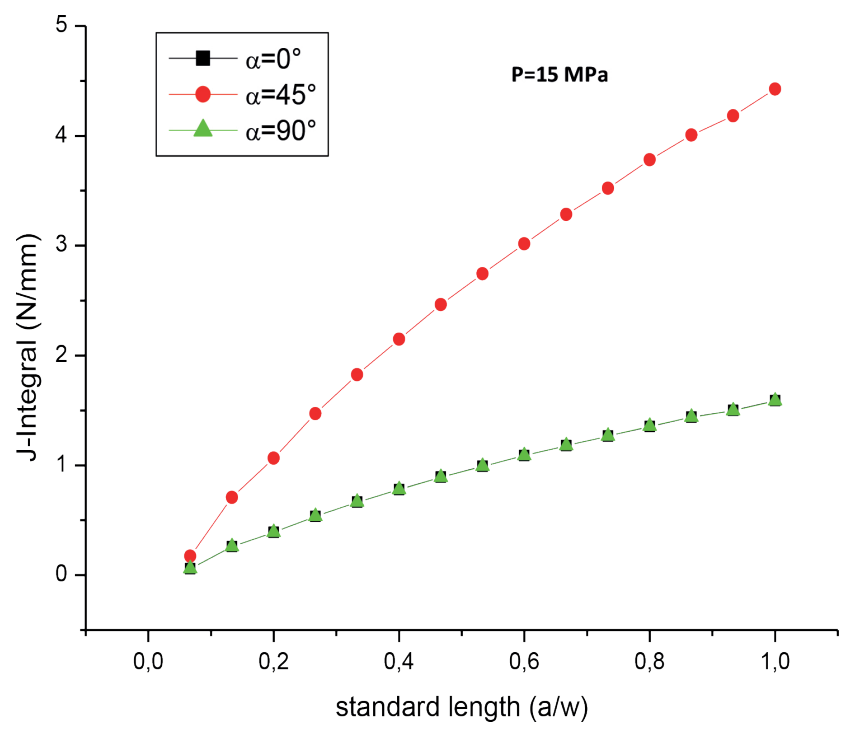

(c)

Fig. 6 Variation of the $J$-Integral as a function of the normalized length

\section{Conclusions}

In service, pipelines are subjected to permanent or irregular mechanical stresses, giving rise to varying stresses and amplitudes, which lead to the appearance of cracks causing their damage or their ruptures. Repair by composite patch remains the most suitable method to prevent any propagation of its cracks which could lead to the rupture of pipelines.

Our work in the repair of a composite patch crack in a pipeline has allowed us to show that the patch allows the reduction of the stress intensity factor by absorbing some of the stresses.

The nature of the composite plays a role in reducing the $J$-Integral. The patch with high mechanical properties better absorbs the stresses in the damaged area and thus minimizes the value of $J$, and this characteristic presents the maximum value for the case of $45^{\circ}$ fiber orientation tends that this value is almost the same for orientations equal to $0^{\circ}$ and $90^{\circ}$ due to the fiber structure. 


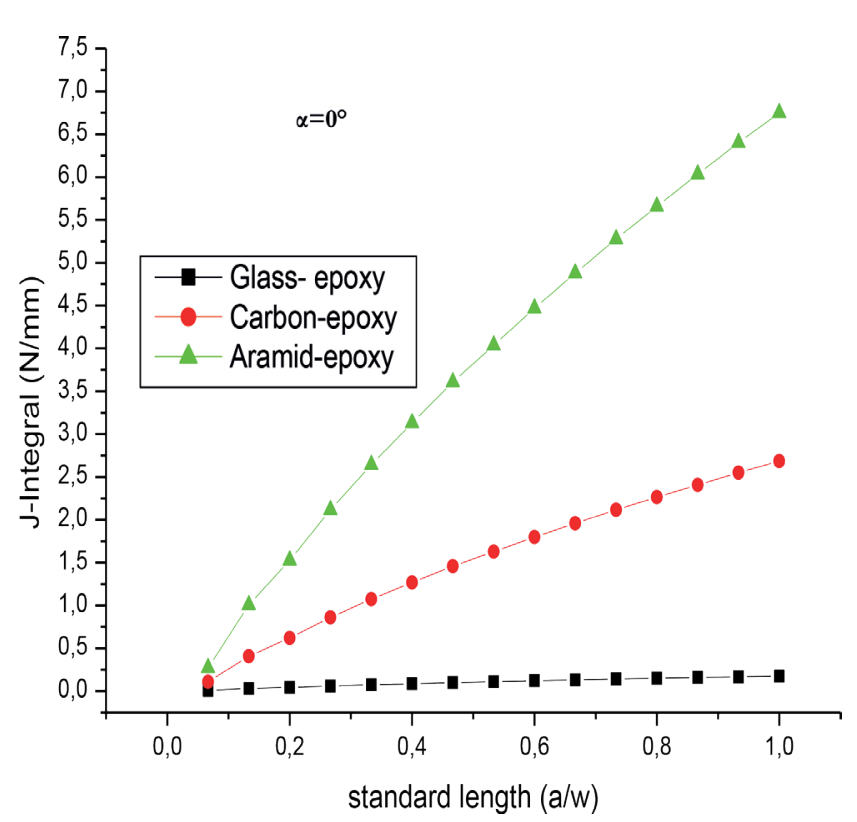

(a)

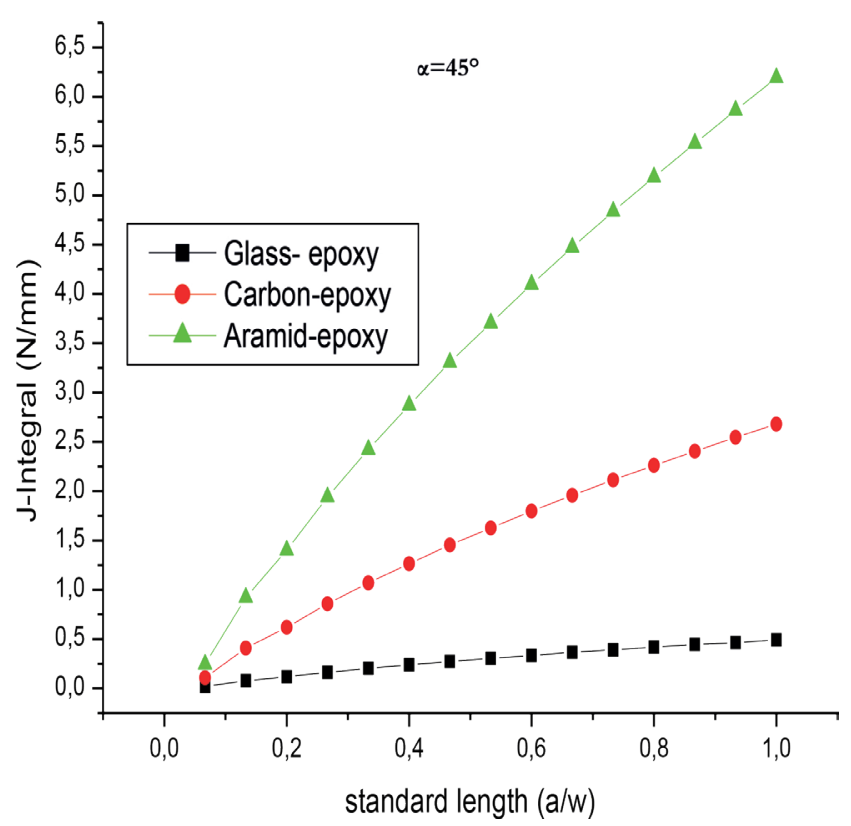

(b)

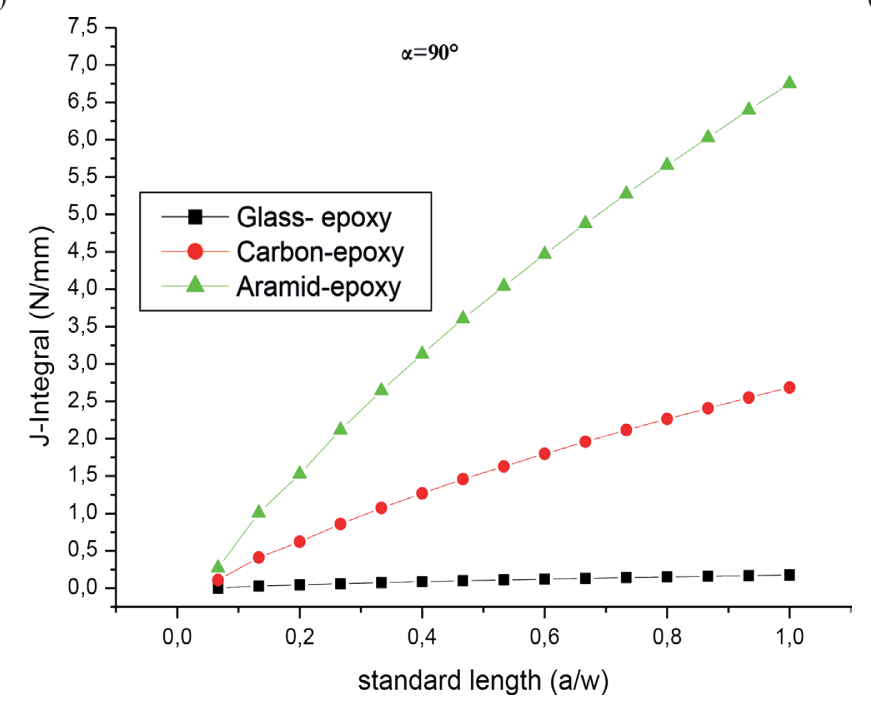

(c)

Fig. 7 Variation of $J$-Integral according to the length

\section{References}

[1] EL-Bagory, T. M. A. A., Younan, M. Y. A., Sallam, H. E. M., AbdelLatif, L. A. "Plastic Load of Precracked Polyethylene Miter Pipe Bends Subjected to In-Plane Bending Moment", Journal of Pressure Vessel Technology, 135(6), Article Number: 061203, 2013. https://doi.org/10.1115/1.4024658

[2] EL-Bagory, T. M. A. A., Sallam, H. E. M., Younan, M. Y. A. "Evaluation of Fracture Toughness Behavior of Polyethylene Pipe Materials", Journal of Pressure Vessel Technology, 137(6), Article Number: 061402, 2015. https://doi.org/10.1115/1.4029925

[3] EL-Bagory T. M. A. A., Sallam, H. E. M., Younan, M. Y. A. "Effect of strain rate, thickness, welding on the $J-R$ curve for polyethylene pipe materials", Theoretical and Applied Fracture Mechanics, 74, pp. 164-180, 2014.

https://doi.org/10.1016/j.tafmec.2014.09.008
[4] Abd-Elhady, A. A., Sallam, H. E. D. M., Mubaraki, M. A. "Failure Analysis of Composite Repaired Pipelines with an Inclined Crack under Static Internal Pressure", Procedia Structural Integrity, 5, pp. 123-130, 2017.

http://doi.org/10.1016/j.prostr.2017.07.077

[5] Kuliczkowska, E., Gierczak, M. "Buckling failure numerical analysis of HDPE pipes used for the trenchless rehabilitation of a reinforced concrete sewer", Engineering Failure Analysis, 32, pp. 106-112, 2013. https://doi.org/10.1016/j.engfailanal.2013.03.007

[6] Gierczak, M. "The qualitative risk assessment of MINI, MIDI and MAXI horizontal directional drilling projects", Tunnelling and Underground Space Technology, 44, pp. 148-156, 2014. http://doi.org/10.1016/j.tust.2014.07.010 
[7] Zhang, C., Moore, I. D. "Nonlinear mechanical response of high density polyethylene. Part I: Experimental investigation and model evaluation", Polymer Engineering and Science, 37(2), pp. 404-413, 1997.

http://doi.org/10.1002/pen.11683

[8] Zhang, C., Moore, I. D. "Nonlinear mechanical response of high density polyethylene. Part II: Uniaxial constitutive modeling", Polymer Engineering and Science, 37(2), pp. 414-420, 1997. http://doi.org/10.1002/pen.11684

[9] Frank, A., Hutař, P., Pinter, G. "Numerical Assessment of PE 80 and PE 100 Pipe Lifetime Based on Paris-Erdogan Equation", Macromolecular Symposia, 311(1), pp. 112-121, 2012. http://doi.org/10.1002/masy.201000096

[10] Pinter, G., Arbeiter, F., Berger, I., Frank, A. "Correlation of fracture mechanics based lifetime prediction and internal pipe pressure tests", In: Plastic Pipes XVII, Chicago, IL, USA, 2014, pp. 1-10. https://doi.org/10.13140/RG.2.1.2210.8563

[11] Benhamena, A., Bouiadjra, B. B., Amrouche, A., Mesmacque, G., Benseddiq, N., Benguediab, M. "Three finite element analysis of semi-elliptical crack in high density poly-ethylene pipe subjected to internal pressure", Materials \& Design, 31(6), pp. 3038-3043, 2010. http://doi.org/10.1016/j.matdes.2010.01.029

[12] Muthanna, B. G. N., Bouledroua, O., Meriem-Benziane, M., HadjMeliani, M., Pluvinage, G., Suleiman, R. K. "Numerical study of semi-elliptical cracks in the critical position of pipe elbow", Frattura ed Integrità Strutturale, 13(49), pp. 463-477, 2019. http://doi.org/10.3221/IGF-ESIS.49.44

[13] Belhadri, D. E., Belhamiani, M., Bouzitouna, W. N., Oudad, W. "Stress intensity factors analyses for external semi-elliptical crack for repaired gas-pipeline by composite overwrap under pressure", Frattura ed Integrità Strutturale, 13(49), pp. 599-613, 2019. http://doi.org/10.3221/IGF-ESIS.49.55

[14] Draï, A., Aour, B. "Analysis of plastic deformation behavior of HDPE during high pressure torsion process", Engineering Structures, 46, pp. 87-93, 2013. http://doi.org/10.1016/j.engstruct.2012.06.033

[15] Qing, X. P., Beard, S. J., Kumar, A., Hannum, R. "A real-time active smart patch system for monitoring the integrity of bonded repair on an aircraft structure", Smart Materials and Structures, 15(3), pp. N66-N73, 2006. http://doi.org/10.1088/0964-1726/15/3/N03
[16] Kilic, B., Madenci, E., Ambur, D. R. "Influence of adhesive spew in bonded single-lap joints", Engineering Fracture Mechanics, 73(11), pp. 1472-1490, 2006. http://doi.org/10.1016/j.engfracmech.2005.12.015

[17] Kaci, D. A., Madani, K., Mokhtari, M., Feaugas, X., Touzain, S. "Impact of composite patch on the J-integral in adhesive layer for repaired aluminum plate", Advances in aircraft and spacecraft science, 4(6), pp. 679-699, 2017. http://doi.org/10.12989/aas.2017.4.6.679

[18] Benyahia, F., Albedah, A., Bachir Bouiadjra, B. A., Belhouari, M. "A Comparison Study of Bonded Composite Repairs of ThroughWall Cracks in Pipes Subjected to Traction, Bending Moment and Internal Pressure", Advanced Materials Research, 1105, pp. 41-45, 2015.

https://doi.org/10.4028/www.scientific.net/AMR.1105.41

[19] Heisterkamp, F., Carneiro, T. "Niobium: Future possibilitiesTechnology and the Market Place", In: The International Symposium on Niobium Science \& Technology, Orlando, FL, USA, 2001, pp. 1109-1159. [online] Available at: https://niobium. tech/-/media/niobiumtech/attachments-biblioteca-tecnica/nt niobium-future-possibilities-technology-and-the-market-place. pdf [Accessed: 17 May 2020]

[20] Hibbitt, Karlsson \& Sorensen, Inc. "ABAQUS/CAE User's Manual", Providence, RI, USA, U.S. Patent 5,920,491, 2000.

[21] Elgued, T., Gravouil, A., Combescure, A. "Appropriate extended functions for X-FEM simulation of plastic fracture mechanics", Computer Methods in Applied Mechanics and Engineering, 195(7-8), pp. 501-515, 2006. http://doi.org/10.1016/j.cma.2005.02.007

[22] Sharba, M. J., Leman, Z., Sultan, M. T. H. "4 - Fatigue life prediction of textile/woven hybrid composites", In: Jawaid, M., Thariq, M., Saba, N. (eds.) Durability and Life Prediction in Biocomposites, Fibre-Reinforced Composites and Hybrid Composites, Woodhead Publishing, Kidlington, UK, 2019, pp. 63-82. http://doi.org/10.1016/B978-0-08-102290-0.00004-0

[23] Sharma, A. P., Khan, S. H., Velmurugan, R. "Effect of through thickness separation of fiber orientation on low velocity impact response of thin composite laminates", Heliyon, 5(10), Article Number: e02706, 2019. http://doi.org/10.1016/j.heliyon.2019.e02706 